\title{
Dacryocyte Analysis
}

National Cancer Institute

\section{Source}

National Cancer Institute. Dacryocyte Analysis. NCI Thesaurus. Code C64801.

The determination of the presence or absence of dacryocytes, abnormal erythrocytes shaped like a teardrop, seen in myelofibrosis and certain other myeloproliferative diseases. 